\title{
STABILISASI TANAH LEMPUNG DENGAN VARIASI PENAMBAHAN POTONGAN LIMBAH BAN, SEMEN, DAN FAKTOR AIR SEMEN DITINJAU DARI PENGUJIAN KUAT TEKAN TAK TERKEKANG YANG DIANALISIS DENGAN ANALISIS SENSITIVITAS
}

\author{
Ida Agustin Nomleni ${ }^{1)}$, Raden Harya Dananjaya ${ }^{2)}$, Yusep Muslih Purwana ${ }^{2)}$ \\ 1) Mahasiswa Program Studi S1 Teknik Sipil Universitas Sebelas Maret Surakarta \\ 2) Staff Pengajar Program Studi S1 Teknik Sipil Universitas Sebelas Maret Surakarta \\ Jalan Ir. Sutami No.36A Surakarta 57126. Telp. (0271)647069. Email: idaagustin.n@student.uns.ac.id
}

\begin{abstract}
Based on data reported by the Indonesian Central Bureau of Statistics, there was an increase in the number of motorized vehicles from 2014 until 2017. The increasing number of motorized vehicles has led to an increase in the amount of vehicle tire waste. An effective method of utilizing tire waste is by using it as a mixture in geotechnical construction materials. This study uses high plasticity clay soil stabilized with pieces of tire waste cut into $1 \mathrm{~mm} \times 1 \mathrm{~mm} \times 30 \mathrm{~mm}$ with variations of $0 \%, 1.5 \%, 3 \%, 4.5 \%, 6 \%$, and $7.5 \%$ of dry weight of soil, cement with variations of $10 \%, 15 \%$, and $20 \%$ of dry weight of soil, and water-cement ratio with variations are $25 \%, 35 \%$, and $45 \%$ of dry weight of cement. Unconfined compressive strength test was carried out to determine the compressive strength. Test results showed that there was an increase in the value of compressive strength using variations of pieces of tire waste, cement, and water-cement ratio. Sensitivity index is the ratio between output to parameter change. Sensitivity index can be used as input in a sensitivity analysis. A large sensitivity index value indicates that the ratio of change is large.
\end{abstract}

Keywords: soil stabilization, unconfined compressive strength, sensitivity analysis, sensitivity index

\begin{abstract}
Abstrak
Berdasarkan data yang dilansir oleh Badan Pusat Statistik Indonesia, terjadi peningkatan jumlah kendaraan bermotor pada tahun 2014 hingga 2017. Meningkatnya jumlah kendaraan bermotor menyebabkan peningkatan jumlah limbah ban kendaraan. Salah satu cara yang efektif adalah menggunakan limbah ban sebagai campuran bahan konstruksi geoteknik untuk mengurangi jumlah limbah ban kendaraan. Penelitian ini menggunakan tanah lempung plastisitas tinggi yang distabilisasi dengan potongan limbah ban yang dipotong dengan ukuran $1 \mathrm{~mm} \times 1 \mathrm{~mm} \times 30 \mathrm{~mm}$ dengan variasi kadar $0 \%, 1.5 \%, 3 \%, 4.5 \%, 6 \%$, dan $7.5 \%$ terhadap berat kering tanah, semen dengan variasi kadar 10\%, 15\%, dan 20\% dari berat kering tanah, dan faktor air semen dengan variasi $25 \%, 35 \%$, dan $45 \%$ dari berat kering semen. Pengujian kuat tekan tak terkekang dilakukan untuk mengetahui nilai kuat tekan. Hasil pengujian menunjukkan bahwa terjadi peningkatan nilai kuat tekan pada variasi penambahan potongan limbah ban, semen, dan faktor air semen. Indeks sensitivitas merupakan rasio perubahan output terhadap perubahan parameter. Indeks sensitivitas dapat digunakan sebagai input dalam analisis sensitivitas. Nilai indeks sensitivitas yang besar menunjukkan bahwa rasio perubahan besar.
\end{abstract}

Kata Kunci : stabilisasi tanah, pengujian kuat tekan tak terkekang, analisis sensitivitas, indeks sensitivitas

\section{PENDAHULUAN}

Tanah merupakan salah satu pemegang peran penting dalam konstruksi sipil karena semua bangunan berdiri di atas tanah. Tanah lempung plastisitas tinggi merupakan salah satu jenis tanah bermasalah karena memiliki daya dukung yang rendah sehingga perlu adanya stabilisasi untuk meningkatkan daya dukungnya. Stabilisasi merupakan salah satu metode perbaikan tanah untuk meningkatkan sifat teknik tanah, meningkatkan daya dukung tanah, dan mengurangi kompresibilitas tanah. Stabilisasi tanah dapat dilakukan dengan dua cara, yaitu mekanis dan kimiawi. Stabilisasi mekanik dilakukan dengan peralatan mekanik sedangkan stabilisasi kimiawi dengan cara menambahkan bahan kimia ke dalam tanah seperti fly ash, semen, kapur. Peningkatan jumlah kendaraan bermotor di Indonesia menyebabkan peningkatan limbah ban kendaraan bermotor. Limbah ban kendaraan dalam jumlah yang besar dapat menimbulkan berbagai masalah kesehatan bila ditimbun maupun dibakar. Oleh karena itu, diperlukan suatu cara yang efektif dalam mengurangi jumlah limbah ban tersebut. Salah satu cara yang sudah banyak diterapkan baik di dalam maupun di luar negeri adalah penggunaan limbah ban sebagai campuran bahan konstruksi. Penggunaan limbah ban dan bahan kimia sebagai stabilisator dapat meningkatkan nilai daya dukung tanah, khususnya tanah lempung. Penelitian ini merupakan salah suatu upaya stabilisasi tanah lempung plastisitas tinggi dengan melakukan penambahan potongan limbah ban, semen, dan faktor air semen. Penelitian ini diharapkan dapat menjadi pertimbangan dalam stabilisasi tanah lempung plastisitas tinggi dan menjadi solusi penumpukan limbah ban kendaraan. 
Selain itu, digunakan analisis sensitivitas untuk mengetahui nilai indeks sensitivitas optimum yang terjadi pada penambahan potongan limbah ban, semen, dan faktor air semen.

\section{TINJAUAN PUSTAKA}

Beberapa penelitian telah dilakukan dalam upaya stabilisasi dengan menggunakan ban maupun komposit potongan limbah ban dengan semen pada stabilisasi tanah lempung.

Surjandari (2007) melalukan penelitian tentang pengaruh penggunaan potongan limbah ban pada tanah lempung ditinjau dari nilai california bearing ratio (CBR). Ban berserat nilon dipotong dengan ukuran $2 \mathrm{~mm} \times 4 \mathrm{~mm}$ dan ukuran $2 \mathrm{~mm} \times 6 \mathrm{~mm}$. Penelitian tersebut menggunakan persentase campuran potongan ban $0 \%, 2 \%, 4 \%, 6 \%, 8 \%$, dan $10 \%$ dari volume tanah yang dipadatkan pada kondisi basah optimum. Hasil yang didapatkan menunjukkan bahwa nilai CBR menurun pada penambahan potongan ban pada kondisi basah optimum.

Akbulut dkk. (2007) telah melakukan pengujian kuat tekan tak terkekang untuk melihat pengaruh penambahan potongan ban dan serat sintesis pada stabilisasi tanah lempung. Ban dipotong dengan panjang $5 \mathrm{~mm}, 10 \mathrm{~mm}$, dan $15 \mathrm{~mm}$. Persentase campuran potongan ban yang ditambahkan pada benda uji adalah 1\%, 2\%, 3\%, 4\%, dan 5\%. Hasil pengujian menunjukkan adanya pengaruh penambahan potongan ban dan panjang potongan ban pada nilai kuat tekan.

Promputthangkoon dkk. (2013) melakukan penelitian pada tanah lempung yang distabilisasi dengan semen dan potongan ban. Pengujian yang digunakan adalah pengujian kuat tekan tak terkekang dan california bearing ratio. Dari penelitian tersebut dapat diketahui bahwa peniambahan semen dan potongan ban dapat meningkatkan nilai kuat tekan dan CBR.

Yadav dkk. (2017) melakukan penelitian pada tanah dengan klasifikasi CL (clay with medium plasticity) berdasarkan Unified Soil Classification System (USCS). Penelitian dilakukan dengan penambahan crumb rubber dan semen pada tanah lempung CL. Crumb rubber dipotong dengan ukuran $0.8 \mathrm{~mm}$ hingga $2 \mathrm{~mm}$. Penelitian tersebut menggunakan persentase crumb rubber $2.5 \%, 5 \%, 7, .5 \%, 10 \%$ dari berat kering tanah. Hasil penelitian menunjukkan bahwa nilai kuat tekan dan kuat tarik meningkat pada penambahan crumb rubber dan semen.

\section{LANDASAN TEORI}

\section{Indeks Sensitivitas}

Menurut Lenhart (2002), indeks sensitivitas merupakan rasio perubahan parameter terhadap output. Indeks sensitivitas pada penelitian ini dihitung berdasarkan perubahan nilai kuat tekan terhadap perubahan persentase variasi. Semakin tinggi nilai indeks sensitivitas, semakin besar perubahan yang terjadi. Nilai indeks sensitivitas akan menjadi input dalam analisis sensitivitas. Cara menentukan indeks sensitivitas adalah dengan memilih dua titik pada grafik. Indeks sensitivitas garis dihitung dari perubahan nilai pada koordinat y dibagi dengan perubahan nilai pada koordinat $\mathrm{x}$. Jika perubahan nilai $\mathrm{x}$ dan perubahan nilai y sama, maka indeks sensitivitas adalah 1. Jika perubahan nilai $\mathrm{x}$ lebih besar dari perubahan nilai y, maka indeks sensitivitas bernilai lebih kecil dari 1. Jika perubahan nilai $\mathrm{x}$ lebih kecil dari perubahan nilai y, maka indeks sensitivitas bernilai lebih besar dari 1. Pendekatan yang biasa dilakukan pada analisis sensitivitas didasarkan pada hipotesis hubungan linear antara parameter output dan parameter input. Metode ini cukup sederhana dan memberikan kemudahan jika jumlah sampel terbatas. Untuk model non-linier dan non-monoton, ada dua metode yang dapat digunakan yaitu metode Sobol dan Fourier Amplitude Sensitivity Test (FAST). Indeks Sobol dihitung dengan simulasi Monte-Carlo namun membutuhkan sejumlah besar data. Lenhart (2002) menggunakan pendekatan diferensial $\partial \mathrm{y} / \partial \mathrm{x}$ dalam menentukan nilai indeks sensitivitas. Indeks sensitivitas yang dihitung dengan pendekatan diferensial $\partial \mathrm{y} / \partial \mathrm{x}$ menunjukkan bahwa perubahan output dipengaruhi oleh perubahan parameter input. Gambar 1 merupakan skema perubahan perubahan parameter terhadap output pada analisis sensitivitas. 


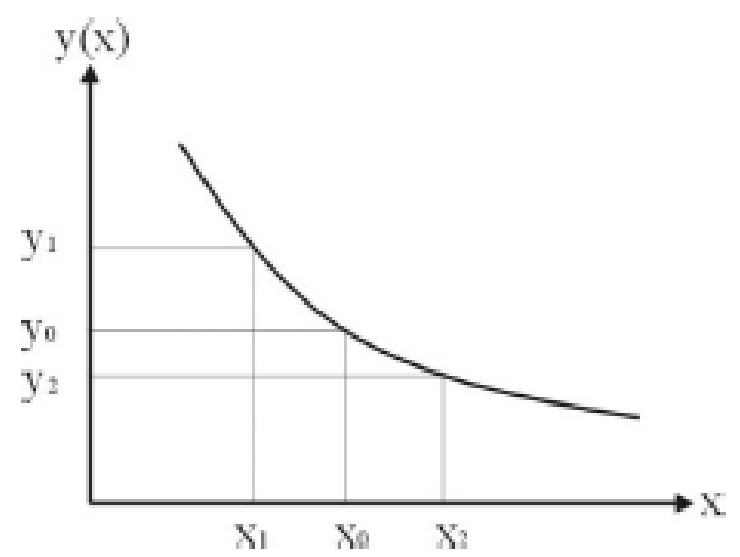

Gambar 1. Hubungan perubahan parameter terhadap output pada analisis sensitivitas

\section{Analisis Sensitivitas}

Analisis sensitivitas merupakan sebuah analisis yang digunakan untuk menganalisa pengaruh perubahan sebuah parameter terhadap nilai optimum sehingga dapat digunakan mencari seberapa pengaruh parameter input terhadap outputnya. Analisis sensitivitas juga dapat digunakan sebagai pengujian model terhadap ketidakpastian sehingga dapat mengetahui kesalahan pada model. Berdasarkan Hamby (1994) terdapat alasan penggunaan analisis sensitivitas antara lain untuk menentukan pengaruh dari parameter input terhadap output, sehingga dapat mengurangi ketidakpastian pada output. Beberapa metode yang diterapkan pada analisis sensitivitas antara lain adalah metode differential sensitivity analysis, one-at-a-time sensitivity analysis, factorial design, sensitivity index, importance factors, dan subjective sensitive analysis. Perhitungan indeks sensitivitas pada penelitian ini didasarkan pada hipotesis hubungan linear antara dan parameter input. Besar indeks sensitivitas didasarkan pada rasio perubahan output model terhadap perubahan parameter karena perhitungan ini menghasilkan indeks sensitivitas yang lebih akurat dan melalui setiap titik data yang dimiliki.

\section{METODE PENELITIAN}

Metode penelitian yang digunakan dalam penelitian ini adalah metode eksperimental laboratorium dan analisis dengan menggunakan analisis sensitivitas. Penelitian ini dilakukan di Laboratorium Mekanika Tanah Fakultas Teknik Universitas Sebelas Maret Surakarta.

\section{Pengambilan Sampel Tanah}

Tanah yang digunakan dalam penelitian ini diambil dari Dusun Ploso, Mojogedang, Karanganyar. Sampel tanah diambil dalam keadaan terganggu (disturbed sample) dengan menggunakan cangkul pada kedalaman 0 hingga 0.5 meter dibawah permukaan tanah. Berdasarkan pengujian pendahuluan, tanah yang diambil dari Dusun Ploso memiliki klasifikasi CH (anorganic clay or bigh plasticity) menurut Unified Soil Classification System (USCS).

\section{Penyediaan Bahan Stabilisasi}

Bahan stabilisasi yang digunakan dalam penelitian ini adalah semen dan potongan limbah ban. Semen yang digunakan dalam penenelitian ini merupakan portland composite cement. Variasi kadar semen yang digunakan adalah $10 \%, 15 \%$, dan $20 \%$ dari berat kering tanah. Limbah ban yang digunakan dalam penelitian ini berupa limbah ban kendaraan bermotor yang dipotong dengan ukuran $1 \mathrm{~mm} \times 1 \mathrm{~mm} \times 30 \mathrm{~mm}$ dengan variasi kadar $0 \%, 1.5 \%, 3 \%$, $4.5 \%, 6 \%$, dan $7.5 \%$ terhadap berat kering tanah. Potongan limbah ban yang digunakan dalam penelitian ini dapat dilihat pada Gambar 2. 


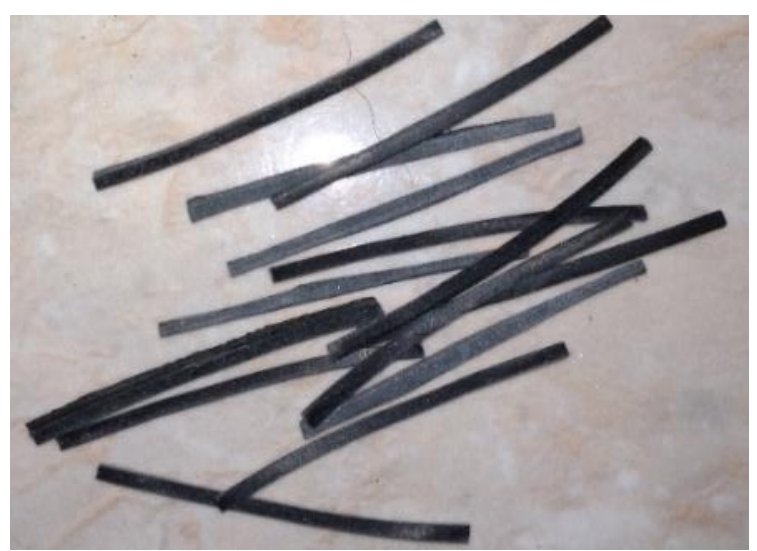

Gambar 2. Potongan limbah ban

\section{Pembuatan Benda Uji}

Tahapan yang dilakukan dalam pembuatan benda uji sebagai berikut: Melakukan pengeringan tanah. Setelah benarbenar kering, tanah ditumbuk dan diayak dengan saringan no. 4. Untuk mengondisikan tanah agar semua benda uji memiliki kondisi yang sama, terlebih dahulu dilakukan pengujian pemadatan dengan modified Proctor. Pemadatan dengan menggunakan modified Proctor akan menghasilkan kurva hubungan kadar air dengan berat volume kering. Tanah yang lolos saringan no.4 kemudian dikondisikan dengan kadar air 24\% dan berat volume kering 1.4 gram $/ \mathrm{cm}^{3}$. Setelah dikondisikan, tanah dicampur dengan semen, potongan limbah ban, dan faktor air semen dengan variasi yang telah ditentukan. Campuran tersebut kemudian dicetak dalam silinder UCS. Benda uji yang digunakan terdiri dari 54 variasi dengan 3 variasi kadar semen, 6 variasi kadar limbah ban, dan 3 variasi faktor air semen. Benda uji yang telah dicetak kemudian diperam selama 3 hari agar terjadi proses pengikatan semen, potongan limbah ban, air, dan tanah.

\section{Pengujian Kuat Tekan Tak Terkekang (UCS)}

Pengujian kuat tekan tak terkekang dilakukan untuk mendapatkan nilai kuat tekan pada kondisi sebelum dan sesudah stabilisasi. Pengujian kuat tekan tak terkekang pada tanah kohesif menggunakan Standar Nasional Indonesia 3638:2012. Hasil pengujian kuat tekan tak terkekang akan menghasilkan grafik hubungan tegangan dan regangan. Nilai kuat tekan pada 54 variasi penambahan semen, potongan limbah ban, dan faktor air semen akan dijadikan input pada analisis sensitivitas.

\section{Analisis Sensitivitas}

Data yang diperlukan sebagai input dalam analisis sensitivitas adalah nilai kuat tekan, persentase potongan limbah ban, persentase semen, dan persentase faktor air semen.

\section{ANALISIS DAN PEMBAHASAN}

\section{Pengujian pendahuluan}

Pengujian pendahuluan bertujuan untuk mengetahui indeks propertis tanah sebelum melakukan stabilisasi. Hasilpengujian pendahuluan indeks propertis tanah Dusun Ploso, Mojogedang dapat dilihat pada Tabel 1.

Tabel 1. Indeks propertis tanah

\begin{tabular}{lll}
\hline Propertis tanah & Notasi & Nilai \\
\hline Berat jenis tanah & $G_{s}$ & 2,66 \\
\hline Batas cair tanah $(\%)$ & $L L$ & 57,94 \\
\hline Batas plastis $(\%)$ & $P L$ & 29,31 \\
\hline Indeks plastisitas & $P I$ & 28,64 \\
\hline Berat volume kering $\left(\mathrm{gr} / \mathrm{cm}^{3}\right)$ & $\gamma_{d}$ opt & 1,404 \\
\hline Kadar air optimum $(\%)$ & $w$ opt & 29 \\
\hline Lolos saringan no. 200 $(\%)$ & & 90,52 \\
\hline Klasifikasi tanah USCS & & $\mathrm{CH}$ \\
\hline
\end{tabular}

Pengujian kuat tekan tak terkekang (UCS) 
Pengujian kuat tekan dilakukan pada tanah tanpa campuran dan pada tanah dengan campuran. Nilai kuat tekan pada tanah tanpa campuran sebesar $42 \mathrm{kN} / \mathrm{m}^{2}$. Grafik hubungan kuat tekan dan regangan pada tanah tanpa variasi penambahan potongan limbah ban, semen, dan faktor air semen dapat dilihat pada Gambar 3.

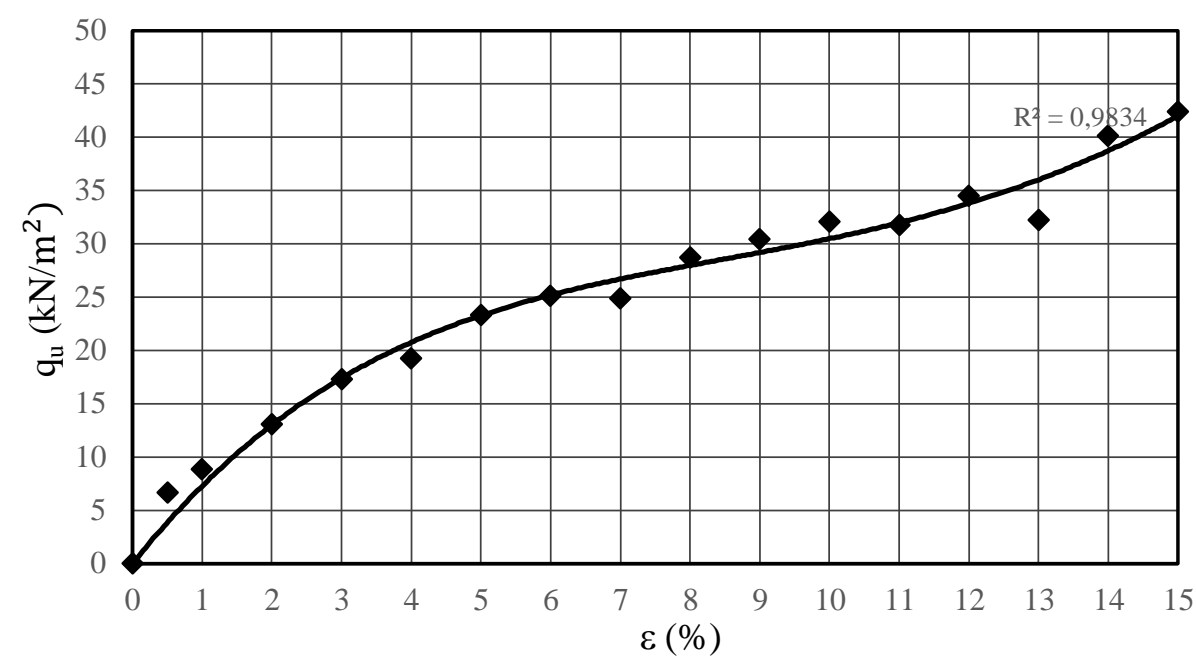

Gambar 3. Hubungan nilai kuat tekan dan regangan pada tanah tanpa variasi

Nilai kuat tekan pada tanah dengan variasi penambahan campuran potongan limbah ban, semen, dan faktor air semen menghasilkan nilai yang lebih besar dibandingkan dengan nilai kuat tekan tanah tanpa penambahan variasi.

\section{Analisis sensitivitas pada penambahan semen}

Untuk mengetahui seberapa besar sensitivitas pada penambahan kadar semen, langkah pertama yang dilakukan adalah membuat grafik hubungan kadar semen terhadap nilai kuat tekan pada variasi penambahan potongan limbah ban dan faktor air semen pada persentase yang sama. Gambar 4 menunjukkan hubungan penambahan kadar semen terhadap nilai kuat tekan pada penambahan $1.5 \%$ potongan limbah ban dan faktor air semen dengan persentase $25 \%, 35 \%$, dan $45 \%$.

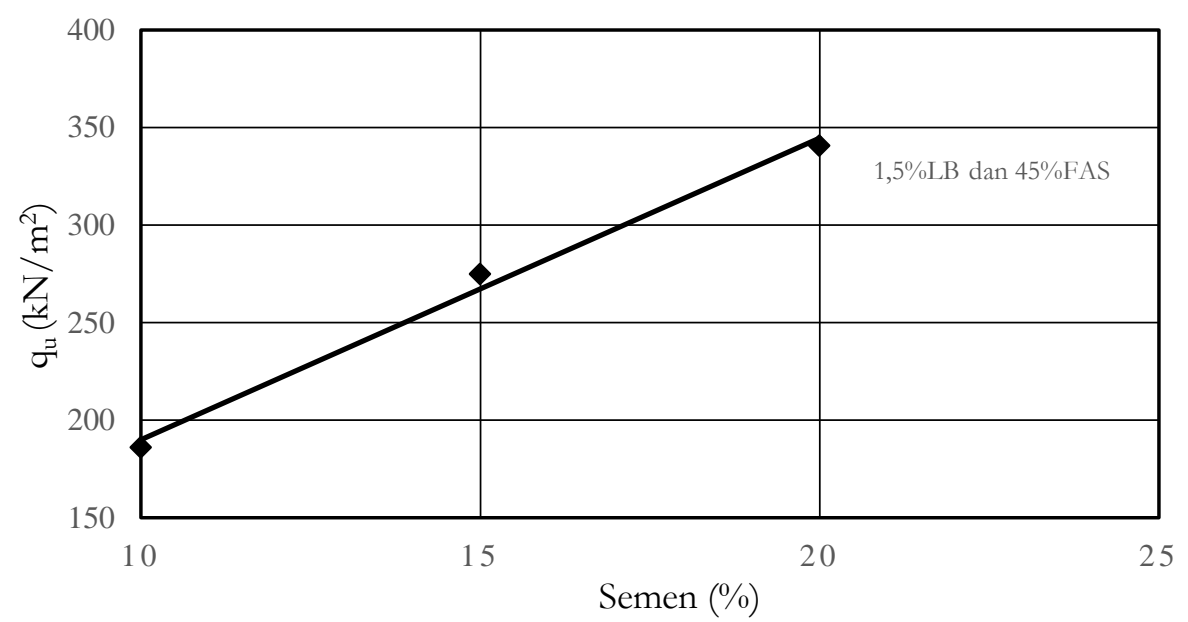

Gambar 4. Hubungan penambahan semen dan nilai kuat tekan pada penambahan $1.5 \%$ limbah ban dan faktor air semen sebesar $35 \%$

Langkah kedua adalah menghitung indeks sensitivitas penambahan semen pada penambahan $1.5 \%$ potongan limbah ban dan dan faktor air semen dengan persentase $45 \%$. Nilai indeks sensitivitas didapatkan dari rasio perubahan nilai kuat tekan terhadap nilai perubahan kadar semen. Nilai indeks sensitivitas penambahan semen pada penambahan $1.5 \%$ potongan limbah ban dan dan faktor air semen dengan persentase $45 \%$ sebesar 15,46.

\section{Analisis sensitivitas pada penambahan air}

Untuk mengetahui seberapa besar sensitivitas penambahan air, langkah pertama yang dilakukan adalah membuat grafik hubungan berat air berdasarkan faktor air semen terhadap nilai kuat tekan pada variasi penambahan 
potongan limbah ban dan semen pada persentase yang sama. Grafik hubungan penambahan air terhadap nilai kuat tekan dapat dilihat pada Gambar 5 pada variasi penambahan 3\% potongan limbah ban dan 15\% semen.

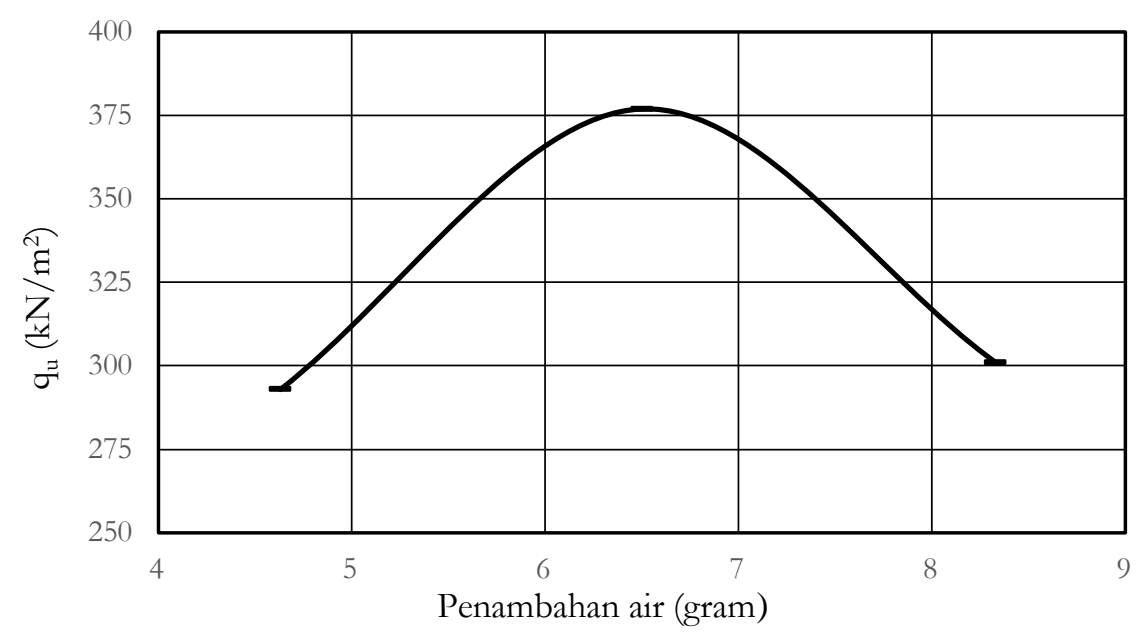

Gambar 5. Hubungan penambahan air terhadap nilai kuat tekan pada variasi penambahan 3\% potongan limbah ban dan $15 \%$ semen

Setelah membuat grafik hubungan penambahan air terhadap nilai kuat tekan, kemudian menghitung indeks sensitivitas dan membuat matriks nilai indeks sensitivitas, persentase potongan limbah ban, dan semen. Nilai indeks sensitivitas penambahan air pada penambahan variasi penambahan 3\% potongan limbah ban dan $15 \%$ semen pada kondisi sebelum optimum sebesar 44.94, sedangkan nilai indeks sensitivitas penambahan air pada penambahan variasi penambahan 3\% potongan limbah ban dan 15\% semen pada kondisi setelah optimum sebesar 41.49 .

\section{Analisis sensitivitas pada penambahan potongan limbah ban}

Tahap pertama dalam melakukan analisis sensitivitas penambahan potongan limbah ban adalah terlebih dahulu membuat grafik hubungan persentase limbah ban terhadap nilai kuat tekan pada variasi persentase penambahan faktor air semen dan semen yang sama. Gambar 6 merupakan grafik hubungan persentase limbah ban terhadap nilai kuat tekan pada penambahan 35\% faktor air semen dan 10\% semen.

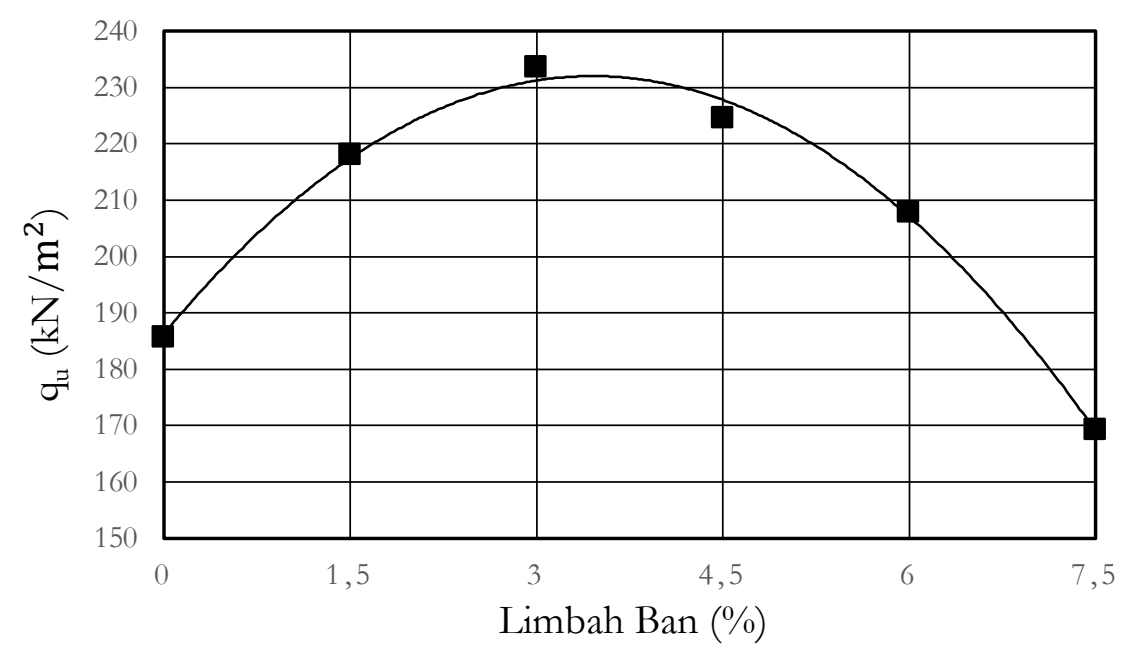

Gambar 6. Hubungan penambahan limbah ban terhadap nilai kuat tekan pada penambahan 35\% faktor air semen dan $10 \%$ semen

Nilai indeks sensitivitas penambahan limbah ban pada penambahan 35\% faktor air semen dan $10 \%$ semen sebelum mencapai nilai optimum sebesar 10.56, sedangkan pada kondisi setelah mencapai nilai optimum sebesar 14.39.

\section{KESIMPULAN DAN SARAN}

Kesimpulan

Kesimpulan yang diperoleh dari hasil penelitian adalah sebagai berikut: 
a. Adanya peningkatan nilai kuat tekan pada variasi penambahan potongan limbah ban, semen, dan faktor air semen pada stabilisasi tanah lempung. Nilai kuat tekan sebelum penambahan variasi sebesar $42 \mathrm{kN} / \mathrm{m}^{2}$.

b. Nilai kuat tekan meningkat dengan adanya variasi penambahan potongan limbah ban, semen, dan faktor air semen.

c. Nilai kuat tekan terbesar pada penambahan potongan limbah ban sebesar 3\%, semen $20 \%$, dan faktor air semen sebesar $35 \%$.

d. Indeks sensitivitas dapat digunakan sebagai input dalam analisis sensitivitas.

e. Nilai indeks sensitivitas semakin meningkat menunjukkan bahwa perubahan output terhadap perubahan parameter semakin besar, apabila nilai indeks sensitivitas kecil maka perubahan output terhadap perubahan parameter kecil.

\section{Saran}

Saran yang dapat diberikan adalah sebagai berikut:

a. Perlu adanya pengujian tambahan, misalnya pengaruh waktu pemeraman terhadap nilai kuat tekan pada variasi penambahan potongan limbah ban, semen, dan faktor air semen.

b. Perlu adanya variasi penambahan potongan limbah ban, semen, dan faktor air semen dengan persentase yang berbeda sehingga menghasilkan data yang beragam.

\section{REFERENSI}

Akbulut, dkk. 2007. "Modification of clayey soils using scrap tire rubber and synthetic fibers". Applied Clay Science 38, pp. 23-32.

Badan Standarisasi Nasional Indonesia. 2012. SNI No 3638:2012 Metode Uji Kuat Tekan Bebas Tanah Kohesif, Indonesia.

Badan Pusat Statistik Indonesia. 2014. Statistik Indonesia 2014. Badan Pusat Statistik ISSN: 0126-2912.

Badan Pusat Statistik Indonesia. 2015. Statistik Indonesia 2015. Badan Pusat Statistik ISSN: 0126-2912.

Badan Pusat Statistik Indonesia. 2016. Statistik Indonesia 2016. Badan Pusat Statistik ISSN: 0126-2912.

Badan Pusat Statistik Indonesia. 2017. Statistik Indonesia 2017. Badan Pusat Statistik ISSN: 0126-2912.

Hamby, D.M. 1994. "A review of techniques for parameter sensitivity analysis of environmental models." Environmental monitoring and assessment 32:135-154, Kuluwer Academic Publisher. "

Lenhart, dkk. 2002. "Comparison of two different approaches of sensitivity analysis." Physics and Chemistry of the Earth 27, pp.645-654.

Promputthangkoon, dkk. 2013. "Geomaterial prepared from waste tyres, soil, and cement". PSU-USM International Conference on Humanities and Social Science 91, pp. 421-428.

Surjandari, N.S. 2007. "Pengarub Penambahan Potongan Ban Berserat Nilon Terbadap Nilai CBR Tanah Lempung”. Media Teknik Sipil Vol. 7, No. 2, pp. 109-114.

Yadav, dkk. 2017. "Assesment of Geotechnical Properties of Uncemented/Cemented Clayey Soil Incorporated With Waste Crumb Rubber". Journal of Material and Engineering Structures, pp. 37-50. 